\title{
Hamsa
}

Journal of Judaic and Islamic Studies

\section{Onomástica en el Libro Hebreo de Henoc: El ángel Metatrón}

Estado de la cuestión

\section{Carlos Santos Carretero}

\section{(2) OpenEdition}

Journals

\section{Edición electrónica}

URL: https://journals.openedition.org/hamsa/649

DOI: $10.4000 /$ hamsa.649

ISSN: 2183-2633

\section{Editor}

CIDEHUS - Centro Interdisciplinar de História Culturas e Sociedades da Universidade de Évora

\section{Referencia electrónica}

Carlos Santos Carretero, «Onomástica en el Libro Hebreo de Henoc: El ángel Metatrón», Hamsa [En línea], 3 | 2017, Publicado el 31 marzo 2017, consultado el 13 mayo 2021. URL: http://

journals.openedition.org/hamsa/649 ; DOI: https://doi.org/10.4000/hamsa.649

\section{(c) (i) (9)}

Hamsa est mise à disposition selon les termes de la Licence Creative Commons Attribution - Pas d'Utilisation Commerciale - Pas de Modification 4.0 International. 


\title{
Onomástica en el Libro Hebreo de Henoc: El ángel Metatrón. Estado de la cuestión
}

\author{
Carlos Santos Carretero \\ Israel Institute of Biblical Studies
}

\section{Resumo:}

O livro hebreu de Enoque (3Enoque) é a última das obras apócrifas atribuídas a Enoque, sétimo patriarca antediluviano. Dos vários trabalhos relacionados com a personagem, 3Enoque é uma obra diferente, focada no elemento místico. Existem inúmeros nomes angelicais nos seus quarenta e oito capítulos, começando com o misteriosa Metatron, que não é outro senão o próprio Enoque transformado em anjo. É descrito como uma figura controversa, também chamado "Javé Menor", e possui vários títulos e funções. A história do nome Metatron tem uma natureza e etimologia muito obscuras, que até hoje têm dividido os pesquisadores.

Palavras-chave: Judaísmo, misticismo, anjos, Enoque, apócrifos

\begin{abstract}
:
The Hebrew Book of Enoch (3Enoch) is the last of the apocryphal works attributed to Enoch, seventh antediluvian patriarch. Of the various works related to the character, 3Enoch is a different work, focused on the mystical element. There are numerous angelic names in its fortyeight chapters, starting with the mysterious Metatron, which is none other than Enoch himself turned into an angel. He is described as a controversial figure also called "The Lesser Yahweh", owning several titles and functions. The story of the name Metatron has a really obscure nature and etymology, which makes researchers disagree even today.
\end{abstract}

Keywords: Judaism, mysticism, angels, Enoch, apocrypha

\section{Las caras de Metatrón}

Uno de los campos de investigación más fecundos en el ámbito de los estudios judíos es el de la literatura apocalíptica. El interés por lo enigmático y lo heterodoxo no es algo nuevo, como bien demuestran los conocidos manuscritos del Mar Muerto en lo referido a escritos rodeados de un cierto halo de misterio ${ }^{1}$. Extensas investigaciones ${ }^{2}$, cuidadas ediciones críticas a

\footnotetext{
${ }^{1}$ Carlos Santos, "El descubrimiento de los manuscritos del Mar Muerto y su digitalización", Caracteres. Estudios culturales y críticos de la esfera digital, 1-1 (2012), p. 26-27.

${ }^{2}$ Annette Yoshiko Reed, Fallen Angels and the History of Judaism and Christianity, Cambridge, Cambridge University Press, 2005.
} 
distintos idiomas ${ }^{3}$, monografías y artículos ${ }^{4}$, congresos y seminarios dedicados a desgranar su contenido, e incluso diccionarios específicos ${ }^{5}$ se han publicado y seguramente seguirán haciéndolo con profusión mientras el ser humano trate de entender y racionalizar los aspectos menos conocidos de la religión.

Dentro de las citadas obras apocalípticas destaca con fuerza el llamado "ciclo de Henoc" o "ciclo henóquico", grupo de obras atribuidas al séptimo patriarca antediluviano del Antiguo Testamento, del que apenas hay menciones en la Biblia, pero que ha dado lugar a una rica literatura ${ }^{6}$.Compuestas a lo largo de varios siglos (su corpus abarca del s. III a.C. al s. VI d.C. ${ }^{7}$ ), estas obras presentan un marco ideal para mostrar las distintas transformaciones a las que se ven sometidos los seres sobrenaturales de la tradición bíblica, así como distintos conceptos escatológicos; todo ello relacionado con la historia de salvación y el fin de los tiempos, así como la posibilidad de que el ser humano ascienda a los cielos en vida y sea capaz de vislumbrar la propia presencia divina. De hecho, a raíz de este aspecto poco a poco se va observando una transformación del género apocalíptico en mística, como bien demuestra la literatura de Merkabah (basada en la contemplación del Carro Divino) ${ }^{8}$. En ella, las descripciones angelológicas van siendo cada vez más detalladas y numerosas, destacando los numerosos nombres angélicos y el significado de los mismos. Justamente en esta etapa de transformación se inserta la obra que sirve de punto de partida para este estudio: El Libro Hebreo de Henoc (cuyo título original es Sefer Hekalot, aunque comúnmente es conocida como 3Henoc).

3 Henoc es un texto que cuenta con dos personajes centrales: Rabí Yišmael y el ángel Metatrón. El primero es uno de los sabios tanaítas de los siglos I y II d.C. El ángel, por su parte, es su guía por los palacios celestiales. ¿Qué tiene de especial este ser angélico frente a la pléyade de criaturas que pueblan las obras de Merkabah? Para empezar, el ángel se presenta como la forma angelizada de Henoc, séptimo patriarca antediluviano mencionado en el libro de Génesis:

\footnotetext{
${ }^{3}$ Alejandro Díez Macho (ed.), Apócrifos del Antiguo Testamento, vols. I-V, Madrid, Ediciones Cristiandad, 1982-87; Joseph T.Milikand M. Black (eds.), The Books of Enoch. Aramaic fragments of Qumran Cave 4, Oxford, Clarenden Press, 1976; Gershom Scholem, Jewish Gnosticism, Merkabah Mysticism, and Talmudic Tradition, New York, Jewish Theological Seminary of America, 1965.

4James Charlesworth VanderKam, "Righteous One, Messiah, Chosen One, and Son of Man in 1 Enoch 3771", in The Messiah: Developments in Earliest Judaism and Christianity, ed. James H. Charlesworth, Minneapolis, Fortress Press, 1992, p. $169-191$.

${ }^{5}$ Gustav Davidson, A Dictionary of Angels, including the Fallen Angels, New York, The Fress Press, 1971.

${ }^{6}$ Existen tres obras fundamentales que configuran los apócrifos vinculados al patriarca: $1 \mathrm{Henoc}, 2 \mathrm{Henoc}$ y 3 Henoc. Conservadas en muy distintas lenguas, aunque provenientes todas de originales hebreos o arameos, se trata de un ciclo literario en el que cada obra es totalmente independiente de las demás, y aunque son consideradas puramente apocalípticas, el componente místico que contienen es enorme (especialmente en 3 Henoc).

7 Henoc (s. III a.C.) y 2 Henoc (s. I d.C.) son obras anteriores insertadas en la apocalíptica judía, mientras que 3 Henoc es una obra posterior, dentro de la literatura de Merkabah, insertada en un contexto diferente a las anteriores, aunque manteniendo a Henoc como figura central.

${ }^{8}$ Desde un punto de vista histórico y teológico, el estudio de la literatura de Merkabah arroja luz acerca de cuestiones que preocupaban enormemente a ciertos círculos judíos, como la relación entre Dios y la Creación, así como los orígenes de la cábala medieval. El origen de este movimiento místico comenzó en Palestina a finales del s. I d. C., especialmente entre los círculos de los fariseos y los tanaítas, con dos figuras centrales: Rabí Aquiba y Rabí Yišmael, grandes maestros de la Halakah en aquella época. De hecho, cuando todas estas tradiciones se ponen por escrito y cristalizan en la llamada "literatura de Hekalot", el carácter pseudoepigráfico y anónimo de estas obras situará a ambos sabios como sus principales protagonistas. De la misma forma que los grandes patriarcas del judaísmo (Adán, Henoc, Abraham, Moisés...) fueron los héroes a los que se atribuía la autoría de numerosas obras apócrifas y apocalípticas, a estos rabinos del s. I d.C. se les considerará autores de las obras místicas que se prodigaron entre los siglos V-VI d.C. - Alejandro Díez Macho (ed.), Apócrifos del Antiguo Testamento, vol. IV, p. 210; Gershom Scholem, Major Trends in Jewish Mysticism, New York, Schocken Books, 1995, p.44.
} 


\begin{abstract}
"Henoc llevaba de vida sesenta y cinco años cuando engendró a Matusalén; y caminó Henoc en compañía de Ha-'Ělohim después de haber engendrado a Matusalén trescientos años, y engendró hijos e hijas. Resultaron pues, todos los días de Henoc trescientos sesenta y cinco años. Ahora bien, Henoc caminó en compañía de Ha-'Ělohim; luego dejó de existir, pues 'Ělohim le tomó consigo"'.
\end{abstract}

"Porque soy Henoc ben Yared. Cuando la generación del diluvio pecó -pues con sus obras se habían corrompido- diciendo a Dios: "Apártate de nosotros, que no queremos saber de tus caminos" (Job 21: 14), entonces el Santo, bendito sea, me sacó de entre ellos para que sirviera de testigo contra ellos ante todos los habitantes del mundo a fin de que no digan: "El misericordioso es cruel, pues qué pecado cometieron todas aquellas multitudes, sus mujeres, sus hijos y sus hijas, sus caballos y sus mulos, sus ganados y haciendas, y todas las aves que en el cielo había; todo lo cual hizo desaparecer del mundo el Santo, bendito sea, por medio de las aguas del diluvio, ¿qué pecado cometieron las bestias y las aves para perecer junto con ellos?" Por esta razón el Santo, bendito sea, me hizo ascender a los altos cielos mientras ellos aún vivían, y ante sus propios ojos, para que sirviera de testigo contra ellos en el mundo futuro, y me nombró príncipe y soberano entre los ángeles servidores".

Sin embargo, la "evolución de Henoc a Metatrón" no sigue un proceso uniforme dentro del ciclo henóquico. En realidad, tanto Henoc como Metatrón son dos figuras en origen independientes que, a lo largo de un complejo proceso de unión de tradiciones terminarán siendo unidas. Tal y como se expondrá en las páginas siguientes, no son pocos los textos en los que se pueden encontrar menciones a Henoc y ninguna a Metatrón, y viceversa. Y esto es lo que ha causado que numerosos investigadores hayan propuesto diferentes teorías e hipótesis tratando de reconstruir los pasos que llevaron a la unión de Henoc y Metatrón, superponiendo una serie de tradiciones y nombres angélicos que van desde elambiente apocalíptico del Segundo Templo hasta la Edad Media. ¿Cuándo tuvo lugar dicha superposición? ¿Bajo qué ambiente religioso se produjo esta amalgama y cuáles son las tradiciones que confluyeron hasta dar lugar al ángel que guía a Rabí Yišmael? ¿Y cuál es el origen del nombre "Metatrón"? Conviene precisar que el presente estudio no buscasolucionar el complejo problema de la etimología de este término, sino dar buena cuenta de las posibilidades y dificultades que se han planteado hasta la fecha. Para ello es preciso, antes de adentrarse en el problema del nombre, aportar algunas notasacerca de la fecha de composición 3 Henoc.

\title{
2. Las teorías sobre la composición de 3Henoc
}

La fecha de redacción exacta de 3Henoc todavía no ha sido resuelta de forma satisfactoria y sigue causando discrepancia en los investigadores, un hecho que viene condicionado generalmente por las diferencias de contenido que se encuentran en los distintos manuscritos del texto y en las versiones impresas del mismo ${ }^{10}$. Parece haber un consenso unánime al situar los capítulos 3Hen 3-16 (los correspondientes a la elevación de Henoc y su transformación en Metatrón) como el núcleo más antiguo de la obra (s.III y IV d.C.) ${ }^{11}$, que seguramente circularon como partes independientes antes de la redacción final de la obra. En torno a ellos surgiría una obra mística con una aparente coherencia interna y mucho más

\footnotetext{
${ }^{9} \mathrm{Gn}$ 5: 21-24.

${ }^{10}$ Philip Alexander,"The Historical Setting of the Hebrew Book of Enoch", Journal of Jewish Studies 28 (1970), p.156.

${ }^{11}$ Alejandro Díez Macho (ed.), Apócrifos del Antiguo Testamento, vol. IV, p. 207.
} 
estructurada que las otras obras henóquicas. Sin embargo, un análisis detallado de todas las partes que componen el texto pone de manifiesto que dicha coherencia no es más que un espejismo, revelándose un texto repleto de contradicciones, especialmente en lo referido a los sistemas angelológicos que presenta.

Por otra parte, aunque también haya conformidad de opiniones al afirmar que $3 \mathrm{Henoc}$ es una de las composiciones de Merkabah y Hekalotmás tardías ${ }^{12}$, aún no se ha obtenido un consenso en torno a la datación de la obra ${ }^{13}$. Como bien indica Alexander "posteriores análisis nos capacitarán para aproximar un poco estos límites, pero en el estado actual de nuestros conocimientos sería probablemente engañarse a uno mismo el pensar que podemos ser mucho más precisos"14.

\section{El ángel Metatrón: A la búsqueda de su origen}

Los citados pasajes de Gn 5: 21-24 y 3Hen 4: 2-5 reflejan el proceso de exaltación y transformación que se ha producido en Henoc a lo largo de la literatura hebrea: de patriarca que camina con Dios y es llevado a los cielos, a un ángel casi sin parangón. Dichos versículos son, en gran medida paralelos a ciertos pasajes del libro de Jubileos ${ }^{15}$. En él también se encuentra la historia de Henoc, quien por su rectitud y fe en Dios fue ascendido a los cielos frente a la maldad de sus coetáneos:

"Henoc estuvo con los ángeles del Señor seis años jubilares. Ellos le mostraron cuanto hay en la tierra, en los cielos y el poder del sol, y lo escribió todo. Exhortó a los "custodios" que habían prevaricado con las hijas de los hombres, pues habían comenzado a unirse con las hijas de loshombres, ydio testimonio contra todos ellos. Fue elevado de entre los hijos del género humano, y lo enviamos al Jardín del Edén para gloria y honor. Y allí está, escribiendo sentencia y juicio eterno y toda la maldad de los hijos de los hombres. Por ello hizo el Señor llegar el agua del diluvio sobre toda la tierra del Edén, pues allí fue puesto él como señal y para que diera testimonio contra todos los hijos de los hombres, narrando sus acciones hasta el día del juicio"16.

\footnotetext{
123 Henoc posee una estructura casi única al encontrarse a medio camino entre la literatura apocalíptica y la mística de Merkabah. Mientras que su contenido pertenece a este último tipo de obras, la forma en la que se expresa no es en absoluto similar a otros escritos como Heḱlot Zutreti o Hekalot Rabbati. Salvo la tradicional recitación de la Qedušah en 3Hen 22B: 8, Sefer Heḱalot carece de himnos litúrgicos en honor a Dios, algo muy habitual en las principales obras de Merkabah y Hekalot. Todo ello, junto con la identificación de Henoc con Metatrón (única obra de Merkabah que lo hace) da a entender que $3 \mathrm{Henoc}$ supone la unión de las tradiciones henóquicas ya existentes con el de la mística del Carro.

${ }^{13}$ Mientras que para Alexander la redacción final podría estar situada en torno al s. IX d.C., Scholem la sitúa entre los s. V-VI d.C., pero sin obviar que gran parte del material es anterior, opinión que comparte con Gruenwald. La hipótesis de Milik, descartada actualmente, considera 3Henoc una obra cabalística de los ss. XII-XIII - Philip Alexander, "The Historical Setting of the Hebrew Book of Enoch", p. 159.

${ }^{14}$ Philip Alexander, "The Historical Setting of the Hebrew Book of Enoch". p. 165.

15 Se trata de un texto canónico para la Iglesia ortodoxa etíope y apócrifo para el resto de iglesias cristianas, así como para el judaísmo. Se considera que fue redactado a finales del s. III a.C. o inicios del s. II a.C. También es denominado Génesis Pequeño o Testamento de Moisés. El texto únicamente se conserva íntegro en ge'ez, y en estado fragmentario en hebreo, griego, latín y hebreo (estos últimos hallados en Qumrán). Recoge las tradiciones henóquicas presentes en $1 \mathrm{Henoc}$, a la vez que reelabora el libro de Génesis, defendiendo un calendario distinto del adoptado por el judaísmo rabínico.

${ }^{16} \mathrm{Jub}$ 4: 21-24. Estos versículos son a su vez una recapitulación de la ascensión de Henoc en Gn 5: 21-24, el pecado de los Vigilantes en Gn 6: 1-4 y el reproche que Henoc hace a Azazel y a los Vigilantes en 1 Hen 13-14.
} 
Esta representación de "Henoc exaltado" está presente a lo largo de todo el ciclo henóquico: En $1 \mathrm{Henoc}$, al personaje se le atribuye el polémico título de "Hijo del Hombre" (1Hen 71: 15), y en 2 Henoc es ungido con el aceite de la gloria de Dios y los vestidos celestiales, siendo indistinguible del resto de ángeles (2Hen 9: 21-23). Sin embargo, fuera del ciclo literario del patriarca también hay menciones a su angelización:

"Subió me al séptimo cielo, y allí vi una luz maravillosa, así como innumerables ángeles.
Vi en aquel lugar a todos los justos (desde Adán; allí vi al santo Abel y a todos los justos;
a Henoc y a todos los que estaban con él), despojados del ropaje carnal. Los vi en sus
excelsas vestiduras (y eran como los ángeles que allí tenían gran gloria, pero no estaban
sentados en sus tronos, ni llevaban sus coronas gloriosas"17.

En el caso de la Ascensión de Isaías, la angelización de Henoc es más bien una comparación con los seres celestiales que un hecho en sí, y recuerda bastante a la unción con aceite de 2 Hen 9. En el texto se observa que Adán, Abel y Henoc poseen vestiduras celestiales y una gran gloria, pero todavía no están sentados en tronos ni poseen sus coronas gloriosas. El propio ángel que acompaña a Isaías en su ascensión por los cielos le revela el motivo de esto:

"Pregunté al ángel que estaba conmigo cómo habían recibido las vestiduras, pero por qué no estaban en los tronos con las coronas. Díjome: "No recibirán las coronas y tronos gloriosos hasta que descienda el Amado en la forma en la que lo verás (pues descenderá al mundo en los días postreros el Señor que ha de llamarse el Cristo). Sin embargo, verán y sabrán de quiénes serán los tronos y coronas de fuego que Él haya descendido, haciéndose como de vuestra forma, (y siendo tenido por carne mortal" ${ }^{18}$.

A lo largo de los citados pasajes puede observarse la exaltación y honor al que es sometido Henoc por parte de los ángeles y del propio Dios. Algunos textos narran únicamente su ascensión debido a su rectitud (Gn 5: 21-24). En otros también recibe el encargo de ser el escriba celestial y dar cuenta de todo lo que ocurre en el mundo (Jub 4: 21-24). 1 Henoc lo eleva a la categoría mesiánica a través del título Hijo del Hombre (1Hen 71: 15). Ascls 9: 9 lo compara con un ángel pero que aún carece de la bendición y la gloria definitiva, y 2 Hen 9: 21-23 no solamente presenta al patriarca ungido e indistinguible del resto de ángeles de Dios, sino que lo sienta a su izquierda y se le otorgan rasgos casi celestiales.

Todos estos pasajes cristalizarían en su forma definitiva en los citados versículos de $3 \mathrm{Hen}$ 4: 2-5, donde Metatrón se revela a R. Yišmael como "Henoc ben Yared", uniendo en un mismo pasaje la elevación del personaje por su rectitud, su función de escriba y la transformación definitiva en ángel. Sin embargo, mientras que en Ascls y $2 \mathrm{Hen}$ la exaltación angélica angelical es mucho menos dramática, en 3 Henoc la elevación y transformación es explícita. Es posible que, de no haber tenido lugar el desarrollo en las obras anteriormente citadas, difícilmente Henoc podría haber sido identificado con Metatrón. Mientras que en los estados previos el personaje nunca es llamado "ángel" como tal (sino que es comparado con ellos o a lo sumo indicado de forma velada), la metamorfosis sufrida en 3 Henoc es total. Henoc y Metatrón se unen en un único ser.

\footnotetext{
17 Ascls 9: 6-10. La Ascensión de Isaías es una obra en origen judía que fue reelaborada por un editor cristiano en su fase final, añadiendo secciones y versículos en referencia a Cristo (mencionado a lo largo del texto como el Amado). La forma definitiva del texto data de la última mitad del s. II d.C., pero algunas de sus partes ya circulaban de forma independiente un siglo antes. El texto original hebreo, hoy perdido, se conservó en griego y etiópico, y de ahí a las posteriores traducciones latinas y eslavas que llevaron a las versiones actuales -F. Corriente Córdoba y L. Vegas Montaner, "Ascensión de Isaías", in Apócrifos del Antiguo Testamento, vol. VI, ed. Alejandro Díez Macho y Antonio Piñero p. 543-576.

${ }^{18}$ Ascls 9: 11-13.
} 
Si Henoc se ve sometido a un largo proceso textual y de exégesis hasta convertirse en Metatrón, ¿cuál es el camino que siguió originalmente este ángel de misteriosa procedencia y que le llevó a unirse con la figura del séptimo patriarca? De la misma forma que Henoc es una reelaboración hebrea del rey Enmeduranki ${ }^{19}$, Metatrón también es un ser compuesto por tres elementos presentes tanto en la literatura apocalíptica hebrea, otras obras de Merkabah e incluso literatura gnóstica cristiana y ciertos encantamientos en óstracas. Dichos elementos son los siguientes: Yaho'el, Yahveh Menor y Metatrón.

$-Y a h o^{\prime} \mathrm{el}^{20}: 3 \mathrm{Hen} 48 \mathrm{D}$ es una larga enumeración de los nombres de Metatrón. El primero de dichos nombres es Yaho'el. El mismo nombre que posee el ángel que acompaña y guía a Abraham en Apocalipsis de Abraham ${ }^{21}$ y le ayuda a superar la tentación de Azazel. De hecho, la relación entre Abraham y Yaho'el es exactamente la misma que mantienen R. Yišmael y Metatrón: el ángel actúa como maestro y protector del hombre. Otro de los puntos comunes que hay entre ambos es que los dos poseen el nombre inefable de Dios en su interior (ApAbr 10:6 $6^{22}$ y 3 Hen $12: 5^{23}$, respectivamente), parafraseando así a Ex 23: 20-21, versículos en los que Dios promete a Moisés que un ángel con su nombre irá en su auxilio. Por último, Yaho'el aparece también en el texto mágico precabalístico conocido como Sefer Ha-Razimcomo uno de los ángeles que pueblan el segundo cielo bajo el nombre יהואל. Se encuentra en la tercera fila de los ángeles de dicho cielo24.

-Yahveh Menor: Entre los títulos que posee el ángel Yaho'el se encuentra el de Yahveh Menor. Este es otro de los rasgos que Metatrón "hereda" de Yaho'el. 3Hen 12: 5 es explícito al respecto, indicando que Dios mismo llama a Metatrón de esta manera. Estas no son las únicas menciones en la literatura hebrea a este título polémico. De hecho, el Alfabeto de Aquiba, en su recensión A, menciona la existencia del Yahveh Mayor ${ }^{25}$, el Dios único, a través de la expresión 'גדול ה', en diferenciación a la de Yahveh Menor. Una dualidad semejante la encontramos también

\footnotetext{
19 Mítico rey mesopotámico que se considera prototipo de Henoc. Presente en las listas de reyes, Enmeduranki ocupa el mismo lugar que Henoc en Génesis (es el séptimo en aparecer), está vinculado a cultos solares y entra en contacto con divinidades como Šamaš y Adad, las cuales le enseñaron secretos, revelaciones, y además le sentaron en un trono dorado. El parecido con Henoc, elevado por Dios y los ángeles, sentado en un trono y colmado de gloria, difícilmente puede ser obviado.

${ }^{20}$ Es preciso recordar que se trata de un nombre doblemente teóforo, ya que en él aparecen las raíces de los dos nombres de Dios que actúan en los relatos de la Creación de Gn 1-3: Yahveh (Yao) y Elohim (El). Todo esto añade una mayor dimensión al compuesto "Henoc-Metatrón" en 3Henoc.

${ }^{21}$ Se trata de un apócrifo eslavo traducido de un escrito griego perdido, y que probablemente proceda a su vez de un original hebreo o arameo que hasta el momento no ha sido encontrado y cuyo contenido ha convencido a los estudiosos para situar su fecha de composición en los años inmediatamente posteriores a la destrucción del Segundo Templo: del 70 d.C. al 120 d.C.

22 "Yo soy Jaoel, así llamado por Aquél que agita lo que está conmigo en el séptimo espacio sobre el firmamento, una virtud por mediación del nombre inefable que está en mí".

23 "El me llamó el "Yahveh menor" ante toda su corte celestial, pues se ha dicho: "Porque mi nombre está en él" (Ex 23:21)".

${ }^{24}$ Harold W. Attridge (ed.), Sepher Ha-Razim. The Book of the Mysteries, traducción de Michael A. Morgan, California, Scholar Press Chico - Society of Biblical Literature, 1983, p.88. En Sefer Ha-Razim se reconoce una fuerte influencia de $2 \mathrm{Henoc}$ y Jubileos, especialmente en lo referido a la revelación de misterios divinos y de medicinas para curas de males, remontándose a los primeros siglos de nuestra era. Margalioth lo data de finales del s.III d.C. y principios del s. IV d.C. - Shifra Sznol, "Sefer Ha-Razim- El Libro de los Secretos. Introducción y comentario al vocabulario griego", Erytheia 10-2 (1989), p.265-267.

${ }^{25} \mathrm{~J}$. Labazahn (ed.), Alfabeto de Aquiba, Varsovia, 1871.
} 
en obras gnósticas ${ }^{26}$ como Pistis Sofia $^{27}$, el Libro de Yeû́ ${ }^{28}$, y Gannat Bussame ${ }^{29}$ (El Jardín de las Delicias) bajo los nombres de "El Gran Yao" y "El Pequeño Yao", respectivamente:

Pistis Sofía es un texto gnóstico cuya versión más antigua está datada del s. II d.C. (el resto se atribuyen a los ss.V-VII d.C.).Describe las enseñanzas de Jesús resucitado a sus discípulos, a su madre, a María Magdalena y a Marta, hermana de Lázaro.

"Y cuando la esfera se revuelve y no viene el pequeño Sabaot, el bueno, al que Ilaman en el mundo Zeus, el cual, entrando en el undécimo eón de la esfera, llamada la del Agua, y Bubastis, entrando en el quinto eón de la esfera, llamada del León, a continuación los que están entre ellos a la izquierda y la derecha se separan a un lado, ya que el Gran Yao, el bueno, que está en medio, preside sobre la región de lachthanabas, y pude mirar hacia atrás, ya que sus regiones pueden ser disueltas y perecer, y todas las almas que se agrupan en sus tormentos puedan ser llevadas adelante mientras se restaura nuevamente la esfera, ya que están pereciendo en sus tormentos"30.

"A través del poder del Pequeño Yao, que está en medio, y el alma del profeta Elías, se unen en el cuerpo de Juan el Bautista"31.

El libro de Yeû es un texto copto que forma parte de los apócrifos del Nuevo Testamento. Redactado en torno al 100 d.C.-300 d.C., está compuesto a su vez por varios textos de carácter iniciático, basado en las palabras de Jesús a sus discípulos tras la resurrección.

\footnotetext{
${ }^{26}$ Es difícil dudar de la relación existente entre el pensamiento gnóstico y los textos de Merkabah, ya que ambos comparten temas similares. No es descabellado pensar que existió una interacción contemporánea entre el misticismo del Carro y la literatura gnóstica, dando lugar a ideas comunes en ambos tipos de pensamiento. También es posible que algún movimiento externo, como un círculo judío auténticamente gnóstico, introdujera estas cuestiones dentro de la literatura de Merkabah. Una tercera posibilidad radica en que gnosticismo y mística hebrea podrían tener una base común de tintes apocalípticos, de la que se fueron distanciando poco a poco, aunque guardaron algunos puntos en común. $Y$ aunque aún es prematuro realizar afirmaciones tajantes, las relaciones entre ambas corrientes de pensamiento posiblemente existan y deberían ser estudiadas en mayor profundidad para entender mejor algunas de las figuras y personajes que aparecen en ambos tipos de obras - Ma Ángeles Navarro, "Libro Hebreo de Henoc", in Apócrifos del Antiguo Testamento, vol. IV, ed.Alejandro Díez Macho p. 214-215. Un posible punto de partida para establecer los puntos en común de estas dos corrientes de pensamiento sería estudiar en conjunto las figuras Yahveh-Metatrón (Merkabah) y Dios Auténtico-Demiurgo (gnosticismo). Dentro de la literatura de Merkabah, Yahveh es el Dios incognoscible y alejado, el fin último, mientras que Metatrón actúa como el vicerregente de los cielos. Por otra parte, el gnosticismo sigue un modelo de teología negativa, presentando a un Dios perfecto e inmanente, inmutable e inaccesible. Por debajo del Dios perfecto gnóstico se encuentra el Demiurgo, amo del mundo material y responsable del origen del mal. Y aunque Metatrón no posea los rasgos negativos que se adscriben al Demiurgo, ambos seres actúan prácticamente como gobernantes de un mundo que no han creado, mientras que Yahveh y el Dios Auténtico están ocultos, y solo a través de la perfección es posible acceder a ellos.

${ }^{27}$ George Robert Stowe Mead (ed.), Pistis Sophia, London., The Theosophical Publishing Society, Aberdeen University Press, 1896, p. XXIX-XXX.

${ }^{28}$ Texto gnóstico de contenido similar a Pistis Sofía, compuesto en copto en torno a los ss. II-IV d.C.Carl Schmidt (ed.), The Books of Jeu and the untitled text in the Bruce Codex, Leiden, Brill, 1978, p. IX-XXI.

${ }^{29} \mathrm{John}$ C. Reeves, Trajectories in Near Eastern Apocalyptic. A Postrabbinic Jewish Apocalypse Reader, USA, Society of Biblical Literature, 2005, p. 185.

${ }^{30}$ George Robert Stowe Mead (ed.) Pistis Sophia, p. 373.

${ }^{31}$ George Robert Stowe Mead (ed.) Pistis Sophia, p. 12.
} 
"De nuevo irás al interior del rango del Gran Yao, el Bueno, el Tesoro de la Luz. Él te dará su misterio, su sello y el gran nombre". ${ }^{32}$

Por último, Gannat Bussame, texto en siríaco del s.X d.C., que contiene una lista de divinidades de finales de la época pre-islámica también menciona al Adonai Mayor y al Adonai Menor ${ }^{33}$ :

"Presto atención solo a una (falsa deidad): el Adonai Menor, líder de las huestes del Adonai Mayor, un necio error venerado por los israelitas" ${ }^{14}$.

La correcta diferenciación entre Yahveh Mayor y Yahveh Menor debe hacerse con mucho cuidado, ya que podría verse como que el cielo está regido por dos divinidades, una superior a otra, pero indicando a fin de cuentas que existen "dos Yahveh". La propia herejía de Aherer ${ }^{35}$ refleja que no eran pocos los que veían en Metatrón a una segunda divinidad como regente de los cielos. No obstante, el título Yahveh Menor no indica en ningún momento que exista más de un Dios en los cielos. De hecho, si se presta atención a la lectura, es el propio Dios el que imbuye a Henoc-Metatrón de este título; otorgándole esa característica que no es sino la sublimación de que dentro de los cielos este ángel cuente con un estatus exaltado. Se trata del "segundo al mando", y para denotar esa importancia, el propio Dios le unge y le otorga de una serie de rasgos próximos a Él, pero siempre sin olvidar que Yahveh Mayor es la única divinidad. El título Yahveh Menor no es sino la forma de indicar la importancia que posee Metatrón en la corte celestial, pero en ningún momento 3 Henoc indica que se trate de otra deidad. De hecho, en el texto hebreo se mencionan otros ángeles con el nombre "Yahveh" en su interior, príncipes que tendrían un estatus, si bien no igual que el de Metatrón, al menos exaltado dentro de las jerarquías celestiales. Estos "Ángeles Yahveh" son los siguientes: Tutresiel Yahveh, Naariel Yahveh, Sasniguiel Yahveh, Zazriel Yahveh, Geburatiel Yahveh, Arafiel Yahveh, Ašruylu Yahveh, Galisur Yahveh, Zakzakiel Yahveh, Anafiel Yahveh, Šoqed Jozí Yahveh, Zehanpuryu Yahveh, Azbugah Yahveh, Soferiel Yahveh, Rikbiel Yahveh, Jayyliel Yahveh, Kerubiel Yahveh, Ofanniel Yahveh, Serafiel Yahveh y Radweriel Yahveh ${ }^{36}$.

Por consiguiente, debe quedar claro queaunque un ángel posea el nombre de Yahveh en su interior, esto no le confiere el estatus de divinidad. Es posible que desde época rabínica hubiera quienes que no supieran vislumbrar la diferencia entre un título exaltado y la categoría de divinidad, dando lugar a las citadas herejías y que llevaron en gran medida a que el ciclo henóquico y el propio Metatrón fueran vistos con malos ojos por la literatura talmúdica y el judaísmo ortodoxo en general.

-Metatrón (מיטטרון): El último de los compuestos empleados para dar lugar al binomio "Henoc-Metatrón" es el propio nombre "Metatrón". Su controversia etimológica ha sido discutida desde hace décadas. Para sabios judíos medievales como Eleazar de Worms o Naḥmánides, Metatrón tiene su origen en el término latino Metator ${ }^{37}$ ("mensajero, líder, medidor, guía"), y que sería transliterado al hebreo como מטיטור o מיטטור.

\footnotetext{
${ }^{32}$ Carl Schmidt (ed.), The Books of Jeu and the untitled text in the Bruce Codex, p.119.

33 Philip Alexander, "The Historical Setting of the Hebrew Book of Enoch", p. 162.

${ }^{34}$ John C. Reeves, Trajectories in Near Eastern Apocalyptic. A Post rabbinic Jewish Apocalypse Reader. Society of Biblical Literature, p. 185.

${ }^{35} 3$ Hen 16: 1-5. Tosefta Hagigah 2:3-4 y Talmud Hagigah $14 \mathrm{~b}$.

36 Hen 18-27.

${ }^{37}$ Hugo Odeberg, 3Enoch or the Hebrew Book of Enoch, Cambridge, University Press, 1928, p.1125-1126.
} 
Orlov $^{38}$ relaciona el nombre del ángel con el aún más oscuro término Prometaya, presente en el texto eslavo Merilo Pravednoe $e^{39} y$ vinculado con el llamado "Príncipe del Mundo" y con el concepto de "medida" o "medidor" (entendiendo este último como "Medidor-Príncipe

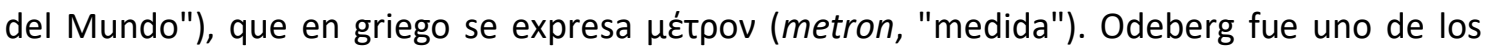
primeros en indicar que Metatrón es un compuesto de las palabras griegas $\mu \varepsilon \tau \dot{\alpha} \theta$ póvo (meta thronos), interpretando el nombre como "El que sirve detrás del Trono" o "El que se sienta en el trono próximo al Trono de la gloria"40. Y aunque de una forma $u$ otra esa haya sido considerada como la interpretación más habitual del nombre Metatrón, en realidad esas palabras griegas no aparecen juntas formando ese nombre en ningún texto conocido ${ }^{41}$.

No obstante, el propio Odeberg no descarta otras posibilidades etimológicas. Jellinek y Jastrow concuerdan con él al afirmar que Metatrón puede provenir del sustantivo arameo מטרא (mattara, "encargado de la vigilancia", o al menos relacionado con los verbos "guardar" y "proteger"42. Una tercera propuesta de Odeberg es la de vincular a Metatrón con el dios persa Mitra ${ }^{43}$, cuyo culto también se extendió por la India y Roma. De hecho, los romanos definieron a este dios con numerosos rasgos no persas y organizaron una religión en torno a él: el mitrianismo. Dicho culto se manifestó en torno al 62 a.C., hasta ser poco a poco abandonado durante el s.IV d.C., tras competir durante años con el cristianismo. De hecho, existen ciertos puntos comunes entre los deberes y funciones de Mitra y Metatrón, dando lugar a unas similitudes que van más allá de lo meramente fonético. Metatrón cumple, dentro de la literatura de Merkabah, el papel de vicerregente de los cielos, sentado en su trono dictando justicia y equidad, siendo únicamente inferior a Dios. Por otra parte, Ahura Mazda u Ormuz, la divinidad benévola del zoroastrismo, tiene en Mitra a su segundo al mando como un valiente guerrero de sus huestes y un mediador, mientras que Metatrón actúa como mediador entre Dios y los hombres. Mitra también sirve como intermediario entre Ahura Mazda y su opuesto, Ahriman o Angra Mainyu, el dios oscuro del zoroastrismo ${ }^{44}$. A su vez, esto recuerda al aspecto mediador de Henocentre Dios y los Vigilantes (1Henoc y $2 \mathrm{Henoc}$ ), los ángeles caídos. Schafer y Lieberman abogan por una interpretación próxima a la de Odeberg, aunque la reformularon indicando que Metatrón significa"el co-ocupante del Trono Divino"45. No obstante, esta etimología tampoco se encuentra en ninguna de las fuentes hebreas en las que aparece el término.

Por último, Alexander también propone dos posibles etimologías del nombre. Al igual que Eleazar de Worms, Naḥmánides u Orlov, Metatrón tendría ese matiz vinculado a "mensajero, medidor y guía", pero para Alexander se remontaría a la palabra latina mitator (de origen griego), utilizada por los oficiales romanos para referirse a los guías y exploradores de los ejércitos, encargados de "medir" el terreno de la batalla ${ }^{46}$. Sin embargo, su segunda teoría

\footnotetext{
${ }^{38}$ Andrei A. Orlov, From Patriarch to the Youth: The Metatron Tradition in 2Enoch, Milwaukee, UMI, 2004, p. 216.

39 Texto eslavo medieval (s. XIII-XIV) que presenta a Henoc como "Gobernador del Mundo". Se trata de un compendio de leyes redactadas por monjes y que tenía como fin servir de guía moral a los jueces. Confiere una gran importancia al concepto de "Medida" y a la transmisión de obras de la Antigüedad.

40 Philip Alexander, "The Historical Setting of the Hebrew Book of Enoch", p. 162.

${ }^{41}$ Gershom Scholem, Major Trends in Jewish Mysticism, p. 69.

42 Hugo Odeberg, 3Enoch or the Hebrew Book of Enoch, p.1125-1126; Adolf Jellinek, Beiträge zur Geschichte der Kabbala, Leipzig, Fritzsche,1852, p. 4; Marcus Jastrow, A Dictionary of the Targumim, the Talmud Babli and Yerushalmi, and the Midrashic Literature, London-New York,Lusac- G.P. Putnam's Sons, 1903, p. 767.

${ }^{43}$ Hugo Odeberg,3Enoch or the Hebrew Book of Enoch, p.1125-1126.

${ }^{44}$ Edward Robinson, The Biblical Repository and Classical Review III (1833), p. 674.

45 Ithamar Gruenwald, Apocalyptic and Merkavah Mysticism, Brill, Leiden, 1980, p. 235-241.

${ }^{46}$ Philip Alexander, "From Son of Adam to a Second God: Transformation of the Biblical Enoch", in Biblical Figures Outside the Bible, ed. Michael E. Stone and Theodore A. Bergren, Harrisburg, Trinity Press International, 1998, p. 102-111.
} 
aboga por resolver la cuestión de un modo simple y tajante: el término Metatrón carece de significado y no sería más que un nombre místico habitual de la literatura de Merkabah, surgido en obras como 3 Henoc y semejante a otros nombres de ángeles aparentemente indescifrables como "Adidirón" o "Dafdafirón"47.

Esta segunda teoría que apunta Alexander tiene puntos muy interesantes para el presente estudio, pero en primer lugar habría que señalar que, aunque Metatrón sea un nombre aparentemente indescifrable y carente de sentido, varias posibilidades etimológicas de las presentadas anteriormente tienen puntos en común. Todas ellas la vinculan al concepto de "guía, mediador o líder". El problema se encuentra en que hasta ahora no se ha trazado un origen etimológico de la palabra que satisfaga a los estudiosos. Si se pudiera datar cronológicamente de forma correcta todas las fuentes en las que aparece el nombre "Metatrón", a partir de ese momento sería mucho más sencillo estudiar las diferentes fases en las que la palabra primigenia fue modificándose hasta tomar la forma actual. El otro punto que debe resaltarse dentro de la hipótesis de Alexander es el de Metatrón como voz mística, cuestión sumamente interesante y cuyo estudio nos permitiría al menos conocer el origen y las bases de la palabra dentro de la literatura de Merkabah. Afortunadamente las investigaciones realizadas hasta la fecha han podido de arrojar algo más de luz. Para ello es necesario consultar otras obras de Merkabah y Hekalot, como Re'uyot Yehzkel:

"¿Qué hay en Zebul ${ }^{48}$ ? R. Levi dijo en nombre de R. Ḥama bar 'Ukba, que dijo en nombre de R. Yoḥanan: El Príncipe no mora en otro sitio sino en Zebul... ¿` cuál es su nombre? Kimos es su nombre. R. Isaac dijo: Me'etah es su nombre. R. 'Inyanei bar Sisson dijo: Bizbul es su nombre. R. Tanḥum dijo: 'Ațațyah es su nombre. Eleazar Nadwadaya dijo: Mițațron, como el nombre del Poder. Aquellos que hacen uso del Nombre dicen: Kas Bas BasKebas es su nombre, como el nombre del Creador del mundo"49.

¿Quién es este Príncipe que cuenta con diversos nombres? Para Scholem está muy claro: Se trata del arcángel Miguel, quien posee varios nombres secretos y místicos ${ }^{50}$. Las similitudes entre Miguel y Metatrón serían las siguientes: ambos tienen una relación muy estrecha con el pueblo de Israel al actuar como su príncipe celestial. Los dos actúan como sumo sacerdote del plano divino, son jefes del resto de ángeles, y lo que se dice de Metatrón en un texto se aplica a Miguel en otro ${ }^{51}$.De este modo, en Re'uyot Yehzkel no solo el término Metatrón (Mițațron) es una voz mística para Miguel, sino que cuenta también con otra serie de nombres de extraño origen (Ǩimos, Me'etah, Bizbul, 'Ațațyah, Kas Bas BasKebas) ${ }^{52}$. Miguel sería el nombre habitual

\footnotetext{
${ }^{47}$ Philip Alexander, "The Historical Setting of the Hebrew Book of Enoch". p. 162.

48 El sexto cielo dentro de la cábala. Por el contrario, en $3 \mathrm{Henoc}$, Zebul es el cuarto cielo: "Šajaquiel, príncipe del ejército, tiene a su cargo el cuarto cielo, que está en Zebul" (3Hen 17: 3).

49 Ithamar Gruenwald, "Re'uyot Yehzkel", in Temirin: Texts and Studies in Kabbala and Hasidism, ed. Israel Weinstock, vol. I, 1972, p. 128.

${ }^{50}$ Gershom Scholem, Jewish Gnosticism, Merkabah Mysticism, and Talmudic Tradition, apéndice C, p. 4445.

${ }^{51}$ Sobre Metatrón:"R. Naḥman dijo: Él, que es tan habilidoso en refutar a los Minim como lo es R. 'Idit, dejad que lo haga; pero no de otra forma. Una vez un Min dijo a R. 'Idit: Y Él dijo a Moisés: Asciende hacia el Señor. Pero seguramente pudo haber dicho: iSube hacia mi! Fue Metatrón [quien dijo esto], replicó, cuyo nombre es similar al de su Maestro, puesto que está escrito: Porque Mi Nombre está en él".(b. Sanh 38b). Sobre Miguel: "Y Miguel, el Príncipe de la Sabiduría, dijo a Moisés en el séptimo día del mes: Subid hacia el Señor, tú y Aarón, Nadab y 'Abihú', y setenta de los ancianos de Israel, y rendiréis culto desde lejos. Y solamente Moisés se acercará al Señor, mas ellos no se acercarán ni subirán con él". (Ps. Jon Ex 24:1).

52 Si se consultara una versión en hebreo del texto, podría estudiarse el origen etimológico de estos nombres. Lamentablemente no se ha contado con la posibilidad de acceder a ella.
} 
para este Príncipe, mientras que Metatrón y el resto de términos serían sus nombres ocultos. No obstante, no hay ninguna identificación directa y explícita entre Miguel y Metatrón en toda la literatura de Merkabah, incluyendo 3 Henoc. De hecho, en la última obra del ciclo henóquico Miguel aparece como el Príncipe a cargo del séptimo cielo y en todo momento se encuentra separado de Metatrón:

"Miguel, el gran príncipe, tiene a su cargo el séptimo cielo, el más alto, que está en Arabot" 53 .

Según la teoría de Scholem y Alexander, en un determinado momento la conexión directa entre Miguel y Metatrón se perdió, y este último se desarrolló como un ángel independiente pero poseyendo muchos de los atributos y rasgos de Miguel ${ }^{54}$. Esta idea ayuda a justificar el hecho de que, dentro de los distintos sistemas angelológicos existentes en las obras de Merkabah no hay un lugar exacto en el que Metatrón sea clasificado. Aunque Metatrón se hubiera escindido de Miguel, este último sigue manteniendo su estatus y posición. Es la voz mística convertida en ángel independiente la que no tiene un lugar exacto en el que posicionarse.

Por consiguiente, se observa que la idea más extendida acerca del origen y formación del compuesto "Henoc-Metatrón" de 3Henoc está formado por una serie de figuras independientes (Henoc, Yaho'el-Yahveh Menor y Miguel-Metatrón) que combinadas dieron lugar a unas de las figuras angelológicas más polémicas y complejas del judaísmo.

¿Por qué habría tenido lugar semejante unión? Actualmente no hay pruebas definitivas acerca de esto, y solo se puede especular y lanzar hipótesis al respecto, pero es conveniente destacar que estas figuras gozaban de cierta relevancia dentro de los distintos movimientos religiosos a los que estaban adscritos. Tanto para judíos como cristianos Henoc ya se consideraba exaltado a través del propio Tanak, 1 Henoc y $2 \mathrm{Henoc}$, Yaho'el cuenta desde el Apocalipsis de Abraham con el rango de Yahveh Menor, y Miguel cuenta con el estatus de Príncipe y regente del séptimo cielo. Si Metatrón fue en origen un nombre místico de Miguel, es posible que esas características tan exaltadas con las que cuenta el arcángel también fueran recibidas por Metatrón en caso de que este se hubiera escindido de Miguel. Quizás la existencia de todas estas figuras constituyera el ambiente propicio para que estas tradiciones fueran unificadas tarde o temprano.

De lo que casi no hay dudas es que Metatrón sería el último elemento en surgir para formar parte de este compuesto que da forma al personaje principal de 3 Henoc. Su mención más temprana tiene lugar en Re'uyot Yehzzel, de inicios del s. IV d.C., donde todavía forma parte de Miguel. Por entonces, tanto la presencia de Henoc como de Yaho'el ya se encuentra reflejada por escrito, y no sería hasta poco después de la escritura de Re'uyot Yehzkel que se comenzase a vislumbrar a Metatrón como un ángel distinto a Miguel. El pasaje de Tb. Sanh 38b indica que el nombre "Metatrón es similar al de su Maestro", y en Re'uyot Yehzzel se observa que "Mițațron [es] como el nombre del Poder, semejante al del Creador del Mundo". Raši señala que, mediante la gematría, el valor numérico de Metatrón es exactamente el mismo que el de Šaddai (Todopoderoso) ${ }^{55}$.

\footnotetext{
53 Hen 17: 3.

54 Philip Alexander, "The Historical Setting of the Hebrew Book of Enoch", p. 163.

55 Raši indica esta asociación entre Metatrón y Šaddai mediante su comentario Éx 23: 21: [Esta cláusula] está conectada al inicio del versículo: Cuidado con él porque "Mi Nombre" está asociado con él. Nuestros sabios, sin embargo, dijeron: Este es [el ángel] Metatrón, cuyo nombre es como el nombre de su Maestro (b. Sanh 38b). El valor numérico de 314 [מטטרון] es igual al de 314 [שדי]. The Complete Jewish Bible with Rashi Commentary. http://www.chabad.org/library/bible_cdo/aid/63255/jewish/The-Bible-withRashi.htm Por el contrario, es muy interesante comprobar que una de las recensiones de $3 \mathrm{Hen} 48 \mathrm{C}$ desvela el valor numérico del título "Yahveh Menor" a través de la propia gematría. A continuación se
} 
Todo esto indica que Metatrón posiblemente fuera en origen uno de los nombres de Dios, y esto es algo que 3 Henoc indica claramente. Es más, el mismo pasaje señala incluso que Yaho'el (el primer ángel en contar con el título de Yahveh Menor, y diversas variantes del mismo nombre) también es un nombre de Dios:

"Setenta nombres tiene Metatrón, los cuales tomó el Santo, bendito sea, de su propio nombre, y se los puso a él. Tales nombres son: Yaho'elYah, Yaho'el, Yofi'el, Yoffie'el, 'Affi'el[...]"

Por otra parte, no está del todo claro cuándo Metatrón absorbió las tradiciones de Henoc y las hizo suyas. Según Hag. 15a, "se le dio permiso a Metatrón para sentarse y escribir los méritos de Israel"57, función atribuida a Henoc en las obras henóquicas previas y tratado en profundidad en las funciones del patriarca en el capítulo siete. Es probable que cuando Metatrón "se unió a Henoc", el primero ya se había escindido de Miguel. No solo no hay menciones que vinculen a Henoc con Miguel, sino que en caso de que estas existieran, posiblemente la figura del séptimo patriarca hubiera alcanzado un nivel de polémica aún mayor que el que actualmente tiene dentro de la tradición hebrea. De este modo llegamos a la conclusión de que la separación definitiva entre Miguel y Metatrón en dos seres diferentes, así como la posterior absorción de los mitos henóquicos por parte de este último ángel tendría lugar en torno a los ss. IV-IX d.C. La ausencia de datos no permite ser más preciso con la información disponible en la actualidad.

\section{Consideraciones finales y perspectivas de estudio}

Pese a ser una de las obras más conocidas de los llamados "apócrifos del Antiguo Testamento", 3Henoc es una obra que sigue causando grandes discrepancias entre los investigadores. Si bien esta obra de Merkabah se ha conservado en hebreo de forma prácticamente íntegra (y en diversas recensiones), cuestiones como el proceso de redacción textual son objeto de estudio desde hace décadas sin llegar a un consenso. Lo mismo puede decirse de la cuestión angelológica, uno de los aspectos fundamentales del texto. A lo largo de este estudio se han analizado las distintas propuestas etimológicas del término Metatrón. Y aunque hasta el momento solo se hayan presentado diversas hipótesis y no se haya alcanzado una conclusión definitiva respecto al origen y desarrollo de este término, las diferentes teorías propuestas han permitido concretar el período de tiempo en el que se desarrolla este nombre, así como su desarrollo posterior y unión a la figura de Henoc y sus tradiciones religiosas.

La investigación en torno a la etimología de este ángel debe continuarse tanto con la propia palabra "Metatrón", así como la extensa lista de nombres presente en 3Henoc 48D: 1-2. Dicha lista refleja la estrecha relación entre Metatrón y Dios en el texto: A Henoc no solo le es concedida la entrada a los cielos en vida, sino que se le convierte en un ángel muy por encima de los demás y cuenta con unos dones únicos, y así lo muestra dicha lista de nombres. El propio Dios dice "setenta nombres tomé de entre mis nombres y con ellos lo llamé para acrecentar su gloria" ${ }^{18}$. En realidad dichos nombres son un total de ciento cinco, siendo posiblemente todos los que se aplicaban a Metatrón en el momento de la redacción del texto. Odeberg apunta que

adjunta una traducción del mismo y el original hebreo:"Y le otorgué Sabiduría e Inteligencia más que a todos los ángeles. Y llamé su nombre "Yahveh Menor", cuyo nombre es mediante la gematría 71".

Hugo Odeberg, 3Enoch or the Hebrew Book of Enoch, p.166.

ומסרתי לו חכמה ובינה יותר מכל המלאכים וקראתי לו יה קטן ששמו בגימטריא ע"א.

56 3Hen 48D: 1.

57 Philip Alexander, "The Historical Setting of the Hebrew Book of Enoch", p. 164.

58 3Hen 48C: 9. 
estos pueden clasificarse en tres grupos ${ }^{59}$ : nombres angélicos, términos variantes de Metatrón y permutaciones del Tetragrámmaton divino. No obstante, en dicha catalogación no se indica qué nombres se corresponden con cada grupo. Actualmente la investigación en torno a esta lista de nombres prosigue. De hecho, en ella es posible encontrar nombres de oscura naturaleza que no guardan relación alguna con la división propuesta de Odeberg, como "voces místicas" (מכרכך) o רוספים, entre otros), así como sustantivos y pronombres (זהק 3 Henoc con una clara connotación religiosa.

Pero Metatrón no es el único ángel destacado que debería estudiarse en $3 \mathrm{Henoc}$. La investigación en torno a los otros ángeles y seres celestiales presentes en la obra ha de ampliarse. Merece la pena señalar la presencia de los "Príncipes Celestiales", jefes de las distintas jerarquías angélicas, así como los llamados "Ángeles Yahveh". El número y descripciones de estos últimos son cuanto menos confusos (la cifra y forma de estos ángeles varía dependiendo del capítulo), y en muchos casos se trata de nombres teofóricos o corrupciones de otros nombres de ángeles, muchos de ellos difícilmente rastreables. Aún hay mucho que decir respecto a esta "onomástica teofórica".

\footnotetext{
${ }^{59}$ AlejandroDíez Macho (ed.), Apócrifos del Antiguo Testamento, vol. IV, p. 288.

60 "Padre".

61 "Valle", "profundidad".

62 "Este" (pronombre demostrativo).
} 